\title{
Loss of occludin leads to the progression of human breast cancer
}

\author{
TRACEY A. MARTIN ${ }^{1}$, ROBERT E. MANSEL ${ }^{2}$ and WEN G. JIANG ${ }^{1}$ \\ ${ }^{1}$ Metastasis and Angiogenesis Research Group, ${ }^{2}$ Department of Surgery, \\ Cardiff School of Medicine, Cardiff University, Cardiff, UK
}

Received May 21, 2010; Accepted July 12, 2010

DOI: 10.3892/ijmm_00000519

\begin{abstract}
Occludin is an integral membrane protein localised at tight junctions (TJs). It has become clear that the TJ is an important structure that cancer cells must overcome in order to metastasize successfully. The purpose of this study was to elucidate the importance of the expression of occludin in human breast cancer. Human tissues and breast cancer cell lines were amplified for functional regions of occludin. Tumour tissues showed truncated and/or variant signals. There was also considerable variation in the expression of occludin in the 10 human breast cancer cell lines investigated. Western blotting demonstrated that variants in the MDAMB-231 and MCF-7 human breast cancer cell lines did not fit the expected occludin signals for changes in phosphorylation status. Immunostaining showed similarly disparate levels of expression. Ribozyme knockdown resulted in increased invasion, reduced adhesion and significantly reduced TJ functions. Q-RT-PCR analysis of 124 tumour and 33 background human breast tissues showed occludin to be significantly decreased in patients with metastatic disease. Immunohistochemical staining showed a decreased expression of occludin in the tumour sections. This study demonstrates for the first time that occludin is differentially expressed in human breast tumour tissues and cell lines. This loss of or aberrant expression has clear repercussions as to the importance of occludin in maintaining TJ integrity in breast tissues. Such inappropriate expression could play a part in breast cancer development.
\end{abstract}

\section{Introduction}

Occludin was the first transmembrane tight junction (TJ) protein to be identified $(1,2)$. It bears 4 transmembrane domains in its $\mathrm{N}$-terminal half, with both the $\mathrm{N}$ - and $\mathrm{C}$ -

Correspondence to: Dr Tracey A. Martin, Metastasis and Angiogenesis Research Group, Department of Surgery, School of Medicine, Cardiff University, Heath Park, Cardiff, CF14 4XN, UK E-mail: martinta1@cf.ac.uk

Key words: occludin, breast cancer, tight junction, metastasis, progression, HGF termini located in the cytoplasm, and the C-terminal $(\sim 150$ amino acids) binding to ZO-1 $(3,4)$. The cytoplasmic domain (domain E) also interacts with both ZO-1 and -2. The topology of occludin predicts 2 extracellular loops projecting into the paracellular space which interacts with loops originating from the occludin protein of the neighbouring cell or unidentified molecules, to promote the interaction and sealing of the paracellular space (5). The C-terminal of occludin is sufficient to mediate endocytosis, as the Cterminal governs the intracellular transport of occludin (6). Occludin is a functional component of the TJ and is widely expressed in both endothelial and epithelial cells, but not in cells and tissues without TJs (7).

The extracellular surface of occludin has been found to be directly involved in cell-cell adhesion and its ability to confer adhesiveness is correlated with the ability to co-localise with ZO-1 (8). The predicted size of occludin is $60-65$ or $82 \mathrm{kDa}$. The discrepancy in the size of occludin protein is a result of differential serine and threonine phosphorylation. The larger phosphorylated form of occludin is found localised within the TJ whereas the smaller, less phosphorylated forms are found in the basolateral membrane and cytosol $(5,9)$. Thus, its phosphorylation is directly related to its function. Small differences in the electrophoretic mobility of occludin are found to be distinct phosphorylated variants with altered membrane localisation, indicating that the phosphorylation of occludin is an important step in TJ assembly (9-11). In endothelial cells, it has been shown that the selective proteolytic cleavage of occludin by metalloproteinases after the inhibition of protein tyrosine phosphatases, raises paracellular permeability (12).

Cancer metastasis proceeds by a series of steps, among which the capacity of cancer cells to invade surrounding normal tissues is of central importance in the dissemination of disease (13). The interaction between cancer and mesothelial cells lining the cavity is crucial for achieving the complex sequence of cancer cell dissemination into the body cavity. In the process of the submesothelial invasion of cancer cells, the TJs of the mesothelial cells can function as a defence against the invasion of cancer cells. Likewise, TJs are also a defense barrier against endothelial invasion (both in intravasation and extravasation), as they are known to work as a barrier to the paracellular passage of cells and substances between the epithelial or endothelial cells (13). Metastasis is the primary cause of fatality in breast cancer 
patients. Although there are believed to be numerous events contributing to the process of metastasis, it is widely accepted that the loss of cell-cell adhesion in the neoplastic epithelium is necessary for the invasion of the surrounding stromal elements and subsequent metastatic events (14).

Early studies have demonstrated a correlation between the reduction of TJs and tumour differentiation, with experimental evidence emerging to place TJs in the frontline as the structure that cancer cells must overcome in order to metastasize (15-18). Although there have been a considerable number of studies on TJs and their role in a number of diseases, it was not till later that their possible role in tumourigenesis was studied. To date most of the studies have concentrated on cell lines, and to a limited degree on colorectal and pancreatic cancers, with only a few studies being carried out on breast cancer concentrating on claudin-1 (SEMP-1), claudin-7, and ZO-1 and -2 expression (14,18-24).

Our previous study demonstrated that the plaque proteins (ZO-1, -2, -3 and MUPP-1) have an altered expression in human breast cancer (24) and that the human breast cancer cell TJ formation can be modulated by a number of factors $(24,25)$. The present study aims to shed light on the way that occludin is expressed in both human breast cancer cell lines and human breast cancer.

Here, we will show that occludin is expressed in variant forms in human breast cancer cell lines and in human breast cancer. We will further demonstrate that the loss of occludin expression after knockdown, results in breast cancer cell lines with a significantly altered phenotype and reduced TJ functionality. We will also illustrate that occludin is lost in human breast cancer tissues and is associated with patient prognosis.

\section{Materials and methods}

Reagents and antibodies. Anti-occludin (N-19, sc-8145 and H-279 epitope, sc-5562) and actin (sc-8432) antibodies were purchased from Pharmingen International (San Diego, CA, USA). Anti-occludin (C-terminal epitope, 71:1,500) antibody was purchased from Zymed (Invitrogen Ltd., Paisley, UK). Peroxidase-conjugated anti-mouse and anti-rabbit IgG for Western blotting were from Sigma-Aldrich Ltd. (Poole, UK). FITC- or TRITC-conjugated anti-mouse, anti-goat and antirabbit IgG were from Sigma-Aldrich. FITC-conjugated dextran $(40 \mathrm{kDa})$ was obtained from Molecular Probe Inc. (Eugene, OR, USA). Carbonate filter inserts with a pore size of $0.4 \mu \mathrm{m}$ (for 24 well-plates) were from Greiner Bio-One Ltd. (Stonehouse, Glos, UK). Gold electrode arrays (8W10E) were purchased from Applied Biophysics Inc. (Troy, NY, USA).

Cell lines. The human breast cancer cell lines MDA-MB231, MCF-10A, BT487, BT549, BT474-KC, MDA-MB-436, MDA-MB-548, MDA MB-435s, ZR751 and MCF-7, were from the American Type Culture Collection (ATCC; Rockville, MD, USA) and the human fibroblast cell line, MRC5, was from the European Collection of Animal Cell Cultures (ECACC, Wiltshire, UK). The human vascular endothelial cell, HECV, was from the Interlab Cell Line Collection (ICLC; Naples, Italy). The cells were routinely

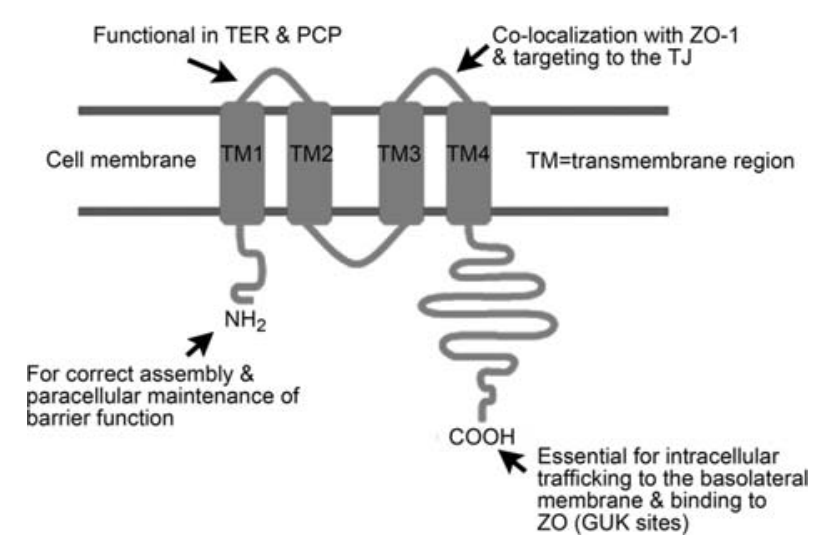

Figure 1. Schematic illustrating the different regions and putative functions of the occludin protein.

maintained in Dulbecco's Modified Eagle's medium (SigmaAldrich) supplemented with $10 \%$ fetal calf serum, penicillin and streptomycin (Sigma-Aldrich).

Conventional PCR. Conventional PCR mix (ABgene, Epsom, Surrey, UK) was used to screen the transcript expression of a number of TJ constituent molecules in human breast cancer cell lines and mammary tissues, with selected control cells. Normal human endothelial cells were used as the positive control. Cycling conditions were as follows: Enzyme activation at $95^{\circ} \mathrm{C}$ for $5 \mathrm{~min}, 1$ cycle, followed by 36 cycles of denaturing at $95^{\circ} \mathrm{C}$ for $15 \mathrm{sec}$, annealing at $55^{\circ} \mathrm{C}$ for $15 \mathrm{sec}$, and then extension at $72^{\circ} \mathrm{C}$ for $2 \mathrm{~min}$. The amplified products were visualised on agarose gels.

Screening of aberrant occludin forms. Tissues and breast cancer cells lines were amplified for functional regions of occludin (Fig. 1). The primer pair Oc1F and Oc1R was designed to span the $\mathrm{N}$-terminus (expected size $616 \mathrm{bp}$ ) OC1F ATGTCATCCAGGCCTC and OC1R ATACACAAT TGTGGCA. The primer pair Oc3F and Oc3R was designed to span the first transmembrane loop (expected size $515 \mathrm{bp}$ ) OC3F GCATCATGGTGTTTATTGC and OC3R GAAGCT CCTGAACCACTTA. The primer pair Oc4F and Oc4R was designed to span the C-terminus (expected size $500 \mathrm{bp}$ ) OC4F GGTTTTATCCAGAGTCTTCCT and OC4R TTGA TGTGTGAACAATTTGCT. Screening was carried out using conventional PCR: Enzyme activation at $95^{\circ} \mathrm{C}$ for $5 \mathrm{~min}, 1$ cycle, followed by 36 cycles of denaturing at $95^{\circ} \mathrm{C}$ for $30 \mathrm{sec}$, annealing at $55^{\circ} \mathrm{C}$ for $30 \mathrm{sec}$, and then extension at $72^{\circ} \mathrm{C}$ for $1 \mathrm{~min}$. The amplified products were visualized on agarose gels. Six paired normal and breast cancer tissues and 10 breast cancer cell lines were assessed to determine the aberrant forms of occludin. In addition, primers were also designed to amplify the full occludin molecule (expected size $1516 \mathrm{bp}$ ) as follows: OCCcodeF1 ATGTCATCCAGGC CTCTT and OCCcodeR1 TCTGTCTATCATAGTCTCCA ACC: Cycling conditions were as follows: Enzyme activation at $95^{\circ} \mathrm{C}$ for $5 \mathrm{~min}, 1$ cycle, followed by 36 cycles of denaturing at $95^{\circ} \mathrm{C}$ for $30 \mathrm{sec}$, annealing at $55^{\circ} \mathrm{C}$ for $30 \mathrm{sec}$, and then extension at $72^{\circ} \mathrm{C}$ for $2 \mathrm{~min}$. The amplified products were visualised on agarose gels. 
Evaluation of occludin promotor hypermethylation. Genomic DNA from multiple sections from frozen tissue and human breast cancer cells was extracted using standard DNA extraction protocol. Methylation-specific PCR was carried out as described previously (26). DNA $(1 \mu \mathrm{g})$ was denatured in $\mathrm{NaOH}$ (to a final concentration of $0.2 \mathrm{M}$ ) for $10 \mathrm{~min}$ at $37^{\circ} \mathrm{C}$, followed by $10 \mathrm{mM}$ of freshly prepared hydroquinone and $3 \mathrm{M}$ sodium bisulfite (at $\mathrm{pH} 5.0$ ). Following incubation at $50^{\circ} \mathrm{C}$ for $16 \mathrm{~h}$, the DNA was purified using the Wizard DNA purification kit (Promega) and standard ethanol precipitation. Hypermethylation was analysed by PCR using the following primers: OCCUMF TACAACACCCAAAACTAAAATACT TTTTCA and OCCUMR TATTTTAGGGTTTTTTTTTGTT TATTTGGTTT for the unmethylated promoters and OCCMF CAACACCCGAAACTAAAATACTTTTC and OCCMR TTTTAGGGTTTTTTTTTGTTTATTCGGTTC for the methylated promoters. Methylation-specific-PCR conditions were as follows: Enzyme activation at $95^{\circ} \mathrm{C}$ for $5 \mathrm{~min}, 1$ cycle, followed by 36 cycles of denaturing at $95^{\circ} \mathrm{C}$ for $15 \mathrm{sec}$, annealing at $58^{\circ} \mathrm{C}$ for $15 \mathrm{sec}$, and then extension at $72^{\circ} \mathrm{C}$ for $30 \mathrm{sec}$. The PCR products were separated on standard $10 \%$ PAGE gels.

Construction of the occludin ribozyme for knockdown experiments. The ribozyme transgene to occludin was constructed as previously reported (28). The following DNA oligos were used to generate the ribozymes: OCCrib1F CTGCAGGC TGGCTGAGAGAGCATTGGTCCTGATGAGTCCGTGAG GA and OCCrib1R ACTAGTGGAGAGATGCATGTTTTC GTCCTCACGGACT. The ribozyme gene cassettes were cloned into the pEF/V5-His TOPO ${ }^{\circledR}$ TA parent vector (Invitrogen). The vectors were transfected into chemically competent Escherichia coli, and bacterial colonies were grown on agar plates. The colonies were examined using the PCR technique to confirm the absence of occludin expression. Plasmid purification and extraction was performed using a plasmid extraction kit (Qiafilter; Qiagen, Crawley, UK). The concentration of each plasmid was determined using a spectrophotometer (WPA UV 1101; Biotech Photometer, Cambridge, UK). MDA MB-231 human breast cancer cells (100 $\mu \mathrm{l})$ were mixed with $10 \mu \mathrm{l}$ of occludin or the control plasmid for $2 \mathrm{~min}$ and were then electroporated at $170 \mathrm{~V}$ with an electroporator (Easyjet; Flowgen). The cells were immediately transferred to complete medium pre-warmed to $37^{\circ} \mathrm{C}$ and plated into 6 well-plates. After $24 \mathrm{~h}$ the cells were transferred to $25 \mathrm{ml}$ cell culture flasks and selected using blasticidin at $5 \mu \mathrm{g} / \mathrm{ml}$. The medium was changed every 3-4 days. After 4 weeks, the cells were transferred to maintenance medium (with $1 \mu \mathrm{g} / \mathrm{ml}$ blasticidin). The occludin knockdown cells were designated as MDA MB-231 ${ }^{\Delta \mathrm{Occ}}$ and MCF-7 ${ }^{\Delta \mathrm{Occ}}$, the wild-type cells MDA MB-231 ${ }^{\mathrm{WT}}$ and MCF-7 ${ }^{\mathrm{WT}}$ and the control plasmid cells MDA MB-231 ${ }^{\text {Plas }}$ and MCF-7 $7^{\text {Plas }}$. Stably transfected cells were then used for subsequent assays (after 6 weeks of culture and confirmation of expression).

In vitro biological assays analyzing occludin knockdown cells. Six assays were used to determine what, if any, the effect of occludin knockdown would have on the human breast cancer cell lines, MDA-MB-231 and MCF-7. Recombinant human HGF was used as a stimulator of invasive behaviour.
Trans-epithelial resistance (TER). TER was measured with an EVOM Voltohmmeter (EVOL; World Precision Instruments, Aston, Herts, UK), equipped with a pair of STX-2 chopstick electrodes (WPI, Sarasota, FL, USA), as we have previously reported $(23,25)$. Briefly, the cells were seeded into the $0.4 \mu \mathrm{m}$ pore size insert (Greiner Bio-One) and allowed to reach full confluence, after which fresh medium was replaced for further experiments. Inserts without cells, inserts with cells in medium and inserts with cells with HGF $(25 \mathrm{ng} / \mathrm{ml})$ were tested for a period of $2 \mathrm{~h}$. Electrodes were placed at the upper and lower chambers and resistance was measured with the voltometer.

Trans-epithelial cell permeability. This was determined using fluorescently labelled dextran FITC-Dextran 40 (SigmaAldrich), the molecular weight being $40 \mathrm{kDa}(23,25)$. Human breast cancer cells were prepared and treated as described above, but with the addition of Dextran-40 to the upper chamber. Medium from the lower chamber was collected for intervals up to $2 \mathrm{~h}$ after the addition of HGF. The relative fluorescence from these collections was read on a multichannel fluorescence reader (Denly, Sussex, UK).

Invasion assay. The invasiveness of the MDA-MB-231 breast cancer cell line was assessed using the following in vitro assay. Transwell chambers equipped with $6.5 \mathrm{~mm}$ diameter polycarbonate filters (pore size $8 \mu \mathrm{m}$ ) (Becton-Dickinson Labware, Oxford, UK) were pre-coated with $50 \mu \mathrm{g}$ / membrane of solubilised basement membrane in the form of Matrigel (Collaborative Research Products, Bedford, MA, USA). After membrane re-hydration, 15,000 cells were aliquoted into each insert with/without HGF. After 96-h coculture, the non-invasive cells were removed with cotton swabs. The invaded cells on the underside of the insert were fixed and stained with crystal violet, followed by microscopic counting (20 fields/insert).

Cell matrix adhesion assay. The cell-matrix attachment assay was carried out as previously reported (27). Briefly, Matrigel (10 $\mu \mathrm{g} /$ well) was added to 96-well plates, which were incubated for $24 \mathrm{~h}$ to allow the binding of the matrix protein to the surface of the well. The plates were then washed and blocked with $5 \%$ bovine serum albumin (Sigma-Aldrich). The cells were added at $10^{4} /$ well for $30 \mathrm{~min}$, followed by aspiration and washing. The number of attached cells was determined by direct counting under a microscope ( 7 counts per experimental setting).

Growth assay. Standard growth assays using crystal violet were carried out over 5 days to determine whether the knockdown of occludin changed the growth rate of MDA-MB-231 and MCF-7 breast cancer cells.

Immunofluorescent staining of human breast cancer cells. For immunofluorescent staining, the cells were grown in 16well chamber slides (Lab-Tek International, Sussex, UK) $\left(30,000\right.$ cells/well) and incubated in a $37^{\circ} \mathrm{C} / 5 \%$ incubator for a set period of time (0-24 h). After incubation, the culture medium was aspirated, the wells were rinsed with balanced salt solution (BSS) buffer and the cells were fixed in methanol 
for $20 \mathrm{~min}$ at $-20^{\circ} \mathrm{C}$. After fixation, the cells were washed twice using BSS buffer and permeabilised by the addition of $200 \mu 1$ of $0.1 \%$ Triton X-100 (Sigma-Aldrich) detergent in phosphate buffered solution for $5 \mathrm{~min}$ at room temperature. The cells were rinsed twice with BSS buffer and $200 \mu 1$ of blocking buffer (10\% horse serum in TBS) was added to each well and the chamber slide was incubated for $40 \mathrm{~min}$ at room temperature on a bench rocker. The wells were washed once with wash buffer (3\% horse serum in TBS buffer containing $0.1 \%$ Tween-20) and $100 \mu 1$ of primary antibodies prepared in wash buffer were added to the appropriate wells. The chamber slide was incubated on the rocker for a further $60 \mathrm{~min}$ at room temperature. The wells were washed twice with TBS buffer (with $0.1 \%$ Tween-20) and the cells were incubated in $100 \mu \mathrm{l}$ of secondary antibodies (fluorescein isothiocyanate or tetramethyl rhodamine iso-thiocyanate conjugates; Sigma-Aldrich) (diluted in the same manner as the primary antibodies) for $50 \mathrm{~min}$. The chamber slide was wrapped in foil to prevent light reaching the conjugate. Finally, the wells were rinsed twice with wash buffer, once in BSS buffer mounted with FluorSave ${ }^{\mathrm{TM}}$ (CalbiochemNovabiochem Ltd., Nottingham, UK) reagent and visualized using an Olympus BX51 microscope with a Hamamatsu (Welwyn Garden City, Herts, UK) Orca ER digital camera at x100 magnification using an oil immersion lens at room temperature (immersion oil by Fluka, Sigma-Aldrich). Images were captured using AnalySIS Five Software (Olympus UK Ltd. Essex, UK) and colourised using Adobe Photoshop CS2.

SDS-PAGE and Western blotting. Total cell lysates and tissues were prepared as follows: The cells were pelleted or the tissue was macerated and lysed in HCMF buffer plus $0.5 \%$ SDS, $0.5 \%$ Triton $\mathrm{X}-100,2 \mathrm{mM} \mathrm{CaCl}, 100 \mu \mathrm{g} / \mathrm{ml}$ phenylmethylsulfonyl fluoride, $1 \mathrm{mg} / \mathrm{ml}$ leupeptin, $1 \mathrm{mg} / \mathrm{ml}$ aprotinin and $10 \mathrm{mM}$ sodium orthovanadate for $40 \mathrm{~min}$, sample buffer was added and the protein boiled at $100^{\circ} \mathrm{C}$ for $5 \mathrm{~min}$ before clarification at $13,000 \times \mathrm{g}$ for $10 \mathrm{~min}$. Equal amounts of protein from each cell sample were added onto an $8 \%$ polyacrylamide gel. Following electrophoresis, the proteins were blotted onto nitrocellulose sheets and blocked in $10 \%$ horse serum for 60 min before probing with specific primary antibodies, followed by peroxidase-conjugated secondary antibody $(1: 2,000)$. The protein bands were visualised with Supersignal West Dura Extended Duration Substrate chemiluminescence system (Perbio Science UK Ltd., Cramlington, UK) and detected using a CCD UVIprochemi system (UVItec Ltd., Cambridge, UK).

In vivo growth assay analyzing occludin knockdown breast cancer cells. The in vivo tumour progression model was adapted from similar previously described protocols $(28,29)$. Briefly, $2 \times 10^{6}$ cells in $100 \mu 1$ were mixed in a $0.5 \mathrm{mg} / \mathrm{ml}$ Matrigel suspension and subcutaneously injected into the left and right flanks of 4-6-week-old athymic nude mice (CD-1; Charles River Laboratories, Kent, England, UK) and allowed to develop. The mice $(n=5)$ were maintained in filter top units and were weighed and the tumour size was measured weekly using Vernier callipers under sterile conditions. Humane endpoints were i) mice which suffered $25 \%$ weight loss, and ii) development of tumours exceeding $1 \mathrm{~cm}^{3}$ [subject to the
Schedule 1 method according to the United Kingdom Home Office and the United Kingdom Coordinating Committee on Cancer Research (UKCCCR) guidelines]. At the conclusion of the experiment, the tumours were measured, the mice were sacrificed as stated under Schedule 1 and the tumours were removed and weighed. Tumour volume was determined using the following formula: Tumour volume $\mathrm{mm}^{3}=0.523 \mathrm{x}$ width ${ }^{2}$ $\mathrm{x}$ length.

Tissue collection and preparation. Breast tissue samples (124 tumour and 33 matched background) (24), were collected and immediately frozen in liquid nitrogen before processing. A portion of each sample was for quantitative-PCR analysis, another for immunohistochemical analysis and a third one for routine histological examination. RNA was isolated from the tissue samples using standard RNA-zol procedures. For RTPCR, cDNA was synthesized in a $20 \mu 1$ reaction mixture using $1 \mu \mathrm{g}$ RNA, as described in the protocol (ABgene Reverse Transcription System, Surrey, UK).

The anonymised breast tissue samples were obtained within the guidlines of the appropriate ethics committee (BFO TAF Health Authority 01/4303 and 01/4046). Informed patient consent was not applicable in this instance (as stated in the Human Tissue Act 2004, UK).

Quantitative-PCR. The Q-PCR system used the Amplofluor ${ }^{\mathrm{TM}}$ Uniprimer $^{\mathrm{TM}}$ system (Intergen Company Oxford, UK) and Thermo-Start ${ }^{\circledR}$ (ABgene). Specific primer pairs for occludin were designed by the authors using Beacon Designer software (Biosoft International, Palo Alto, CA, USA) manufactured by Invitrogen, each amplifying a region that spans at least 1 intron generating an $\sim 100$ base pair product from both the control plasmid and cDNA. The PCR primers were: OCZF GAATTCAAACCGAATCATTG and OCZR ACTGA ACCTGACCGTACATGAAGAATTTCATCTTCTGG. Using the iCycler iQ system (Bio-Rad), which incorporates a gradient thermocycler and a 96-channel optical unit, the plasmid standards and breast cancer cDNA were simultaneously assayed in duplicate reactions using a standard hotstart Q-PCR master mix. Q-PCR conditions were as follows: Enzyme activation at $95^{\circ} \mathrm{C}$ for $12 \mathrm{~min}, 1$ cycle, followed by 60 cycles of denaturing at $95^{\circ} \mathrm{C}$ for $15 \mathrm{sec}$, annealing at $55^{\circ} \mathrm{C}$ for $40 \mathrm{sec}$, and then extension at $72^{\circ} \mathrm{C}$ for $25 \mathrm{sec}$. Using purified plasmids as internal standards, the level of cDNA (copies/50 ng RNA) in the breast cancer samples was calculated. Q-PCR for $\mu$-actin was also performed on the same samples, in order to correct any residual differences in the initial level of RNA in the specimens (in addition to spectrophotometry). The results were then normalized using cytokeratin-19 levels in the same tissues. The products of Q-PCR were verified on agarose gels (data not shown).

Immunohistochemistry. Cryostat sections of frozen tissue were cut at $6 \mu \mathrm{m}$, placed on Super FrostPlus slides (LSL UK, Rochdale, UK), air dried and fixed in a 50:50 solution of alcohol:acetone. The sections were then air dried again and stored at $-20^{\circ} \mathrm{C}$ until use. Immediately before the commencement of immunostaining, the sections were washed in buffer for $5 \mathrm{~min}$ and treated with horse serum for $20 \mathrm{~min}$ as a blocking agent to non-specific binding. The sections were 
stained using occludin antibody (Insight Biotechnology, Wembley, Cambridgeshire, UK). Negative controls were used where necessary. Primary antibodies were used at 1:100 dilution for $60 \mathrm{~min}$ and then washed in buffer. The secondary biotinylated antibody at 1:100 dilution (universal secondary, Vectastain Elite ABC; Vector Laboratories Inc., Burlingham, CA, USA) was added (in horse serum/buffer solution) for $30 \mathrm{~min}$, followed by numerous washings. Avidin/biotin complex was added for $30 \mathrm{~min}$, again followed by washes. Diaminobenzidine was used as a chromogen to visualize the antibody/antigen complex. The sections were counterstained in Mayer's hematoxylin for $1 \mathrm{~min}$, dehydrated, cleared and mounted in DPX. Following this, the sections were analyzed for staining intensity as previously described $(24,25)$.

Statistical analysis. Statistical analysis was performed by the MINITAB version 13.32 (Minitab Inc. State College, PA, USA) using a two-sample Student's t-test and the nonparametric Mann-Whitney confidence interval and test or Kruskal-Wallis, where appropriate. In addition, Microsoft Excel Professional was used to calculate the correlation coefficients and SPSS 12.01 for the survival curves.

\section{Results}

Expression of occludin in human breast tissues and cancer cell lines. Overall, only 6/10 breast cancer cell lines expressed full-length occludin (Fig. 2A). A closer comparison of an invasive (MDA-MB-131, which did not express the fulllength) and a non-invasive (MCF-7, which expressed the full-length) breast cancer cell line was carried out (Fig. 2B) with the human endothelial cell line HECV as the positive control. Both expressed the correct Ocr3 region, although however, they also both expressed the truncated versions. Only a faint signal was observed for the correct Ocr4 region in the MCF-7 cells, which was not observed in the MDAMB-231 cells. Both however, expressed a larger version of $\sim 500 \mathrm{bp}$, which was stronger in the case of the MDA-MB231 cells. This perhaps demonstrates why only a faint signal was shown for MCF-7 but no signal was produced by the MDA-MB-231 cells for the full-length version of occludin. In a small set of human tumour and normal tissues from the same patients, all of the 6 tumour tissues showed truncated and/or variant signals for the N-terminal and first transmembrane loop of occludin (as amplified using the Ocr1 and Ocr3 primer pairs). Four of these 6 tumour tissues did not express the $\mathrm{C}$-terminal region of occludin (as amplified using the Ocr4 primer pairs) (Fig. 2C). However, paired background tissues showed similar expression profiles. Strong methylation of the promoter was not observed (Fig. 2D) and none of the breast tissues showed methylation of the occludin promoter (data not shown). Western blotting demonstrated the expression of variants of occludin when probed with 3 antibodies specific for the $\mathrm{N}$-terminus, first membrane loop and the C-terminus in the MDA-MB-231 and MCF-7 cells (Fig. 2E). The N-terminus precipitated only the $82 \mathrm{kDa}$ form of occludin. The remaining 2 antibodies precipitated the $82 \mathrm{kDa}$ form (only faintly with $\mathrm{H}-279$ ) and also the $65 \mathrm{kDa}$ form, as expected. However, another form of $\sim 70 \mathrm{kDa}$ was precipitated with these antibodies. This variant did not corre- spond to the occludin signals for changes in the phosphorylation status of the protein, and thus it is anticipated that it represents the true variant of occludin.

Knockdown of occludin in human breast cancer cells. The knockdown of occludin expression in both the MDA-MB-231 and MCF-7 cells (MDA-MB-231 $1^{\Delta \mathrm{Occ}}$ and MCF-7 ${ }^{\Delta \mathrm{Occ}}$ ) was confirmed by Western blotting (Fig. 3A) and by immunofluorescent staining (Fig. 3B). The absence of occludin could clearly be observed compared to the wild-type (MDA-MB$231^{\mathrm{WT}}$ and MCF-7 ${ }^{\mathrm{WT}}$ ) and the control plasmid cells (MDAMB-231 $1^{\text {Plas }}$ and MCF-7 $7^{\text {Plas }}$ ) as almost the complete absence of signal in the Western blots. The blot was carried out detecting the N-terminus ( $82 \mathrm{kDa}$ form). Immunofluorescent staining showed the complete loss of occludin staining at both the cell-cell junctions and in the cytoplasm (using the same antibody).

In vitro growth of occludin-knockdown human breast cancer cells. Growth assays were performed over 5-day growth for the knockdown cell lines and their controls. MDA-MB-231 $10 \mathrm{cc}$ showed no difference in growth patterns when compared to the wild-type and the control plasmid groups (Fig. 4A). However, growth was elevated in the MCF-7 ${ }^{\Delta \mathrm{Occ}}$ cells compared to the controls (Fig. 4B) at 2-3 days of growth ( $\mathrm{p}=0.004$ and $\mathrm{p}=0.003 \mathrm{MCF}-7^{\mathrm{WT}}$ and MCF-7 ${ }^{\text {Plas }}$, respectively) but this was abrogated within 5 days, with no noticeable difference in growth rate.

In vitro invasion of occludin-knockdown human breast cancer cells. Invasion assays were carried out to ascertain any effect of the occludin-knockdown in both human breast cancer cell lines. MDA-MB-231 ${ }^{\Delta \mathrm{Occ}}$ showed increased invasion (RDU $0.228 \pm 0.009, \mathrm{n}=10$ ) compared to both the wild-type and control plasmid cells (MDA-MB-231 ${ }^{\mathrm{WT}} 0.205 \pm 0.01, \mathrm{p}=0.019$ and MDA-MB-231 Plas $0.207 \pm 0.01, \mathrm{p}=0.038$ ) (Fig. 4C). Treatment with HGF $(25 \mathrm{ng} / \mathrm{ml})$ elevated this increased invasion (MDA-MB-231 ${ }^{\Delta \mathrm{Occ}} 0.32 \pm 0.005$ vs. MDA-MB-231 wT $0.31 \pm 0.004, \mathrm{p}=0.27$ and vs. MDA-MB-231 $1^{\text {Plas }} 0.27 \pm 0.005$, $\mathrm{p}<0.0001)$. Even though MCF-7 cells are not highly invasive, the knockdown of occludin increased the invasiveness of these cells $\left(\mathrm{MCF}-7 \triangle \mathrm{Occ} 0.055 \pm 0.0005 \mathrm{vs}\right.$. MCF-7 ${ }^{\mathrm{wT}}$ $0.05 \pm 0.009, \mathrm{p}=0.27$ and vs. MCF-7 $7^{\text {Plas }} 0.049 \pm 0.002$, $\mathrm{p}<0.0001)$ (Fig. 4D). HGF (25 ng/ml) magnified this increase in invasiveness $\left(\mathrm{MCF}-7 \triangle \mathrm{Occ} 0.057 \pm 0.0019 \mathrm{vs}\right.$. MCF-7 ${ }^{\mathrm{WT}}$ $0.054 \pm 0.002, \mathrm{p}=0.04$ and $\mathrm{vs} . \mathrm{MCF}-7^{\text {Plas }} 0.052 \pm 0.001$, $\mathrm{p}=0.003$ ). These results were expected, as we have already demonstrated that HGF reduces occludin in these cell lines (23). It is evident that the knockdown of occludin produces a similar physiological effect as the reduced occludin expression.

In vitro adhesion of occludin knockdown human breast cancer cells. The knockdown of occludin in the MDA-MB-231 cells resulted in a remarkable decrease in the adhesiveness to the basement membrane (Fig. 4E) when compared to both the wild-type and plasmid control cells (MDA-MB-231 $4 \mathrm{Occ}$ $0.095 \pm 0.016$ RDU, n=10; MDA-MB-231 ${ }^{\mathrm{wT}} 0.267 \pm 0.004$, $\mathrm{p}=0.0002$; MDA-MB-231 $\left.{ }^{\text {Plas }} 0.268 \pm 0.027, \mathrm{p}=0.002\right)$. HGF $(25 \mathrm{ng} / \mathrm{ml})$ did not cause great change in the knockdown 
A

Occludin expression: full length signal (1516 bp)
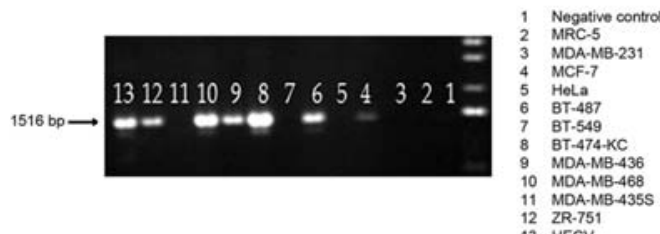

C

Occludin expression in human breast tumour $(\mathrm{T})$ and background/Normal $(\mathrm{N})$ tissues
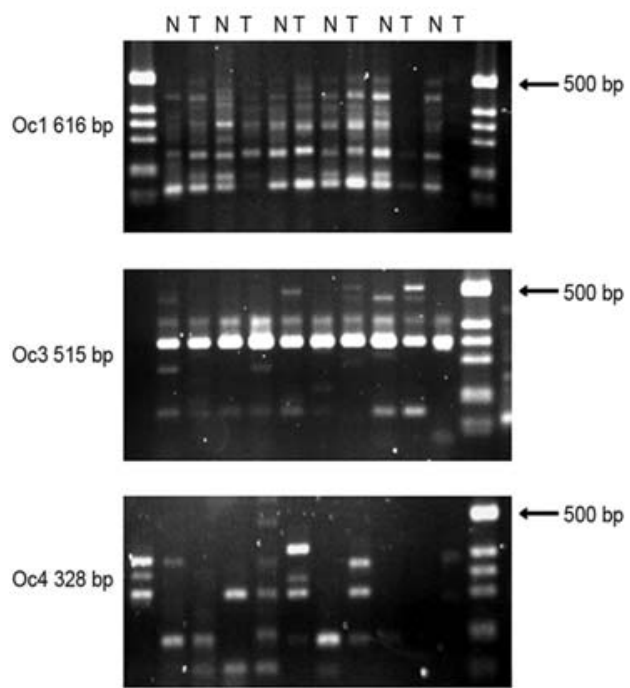

B

Comparison of erroneous expression of Occludin in MDA-MB-231 and MCF-7 cell lines (HECV shown as positive control)

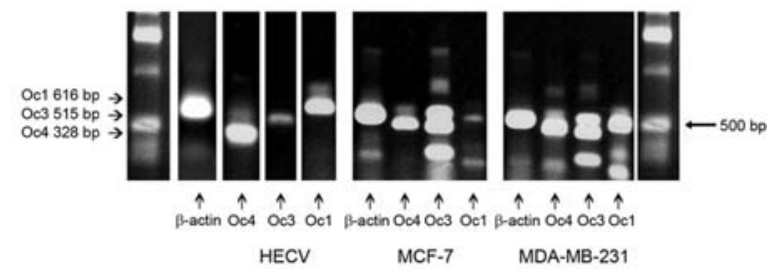

D

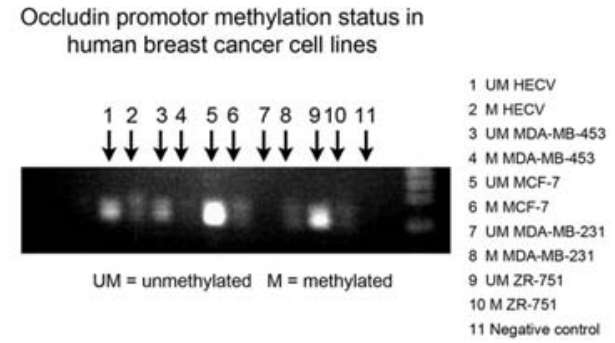

$E$

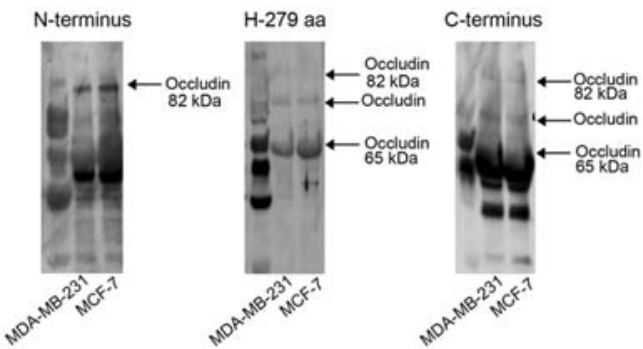

Figure 2. Expression of occludin variants in human breast cancer cell lines and paired human breast tumour/background tissues. (A) Presence or absence of the full occludin transcript in human breast cancer cell lines. (B) A comparison of the differences in expression of variants within the occludin transcript of MDA-MB-231 and MCF-7 human breast cancer cells. Amplification of 3 regions within the occludin transcript (Oc1, Oc3, Oc4) was carried out, with HECV cells as the controls. (C) Amplification of the same 3 regions of occludin in paired tumour/background tissues. (D) Methylation status of the occludin promoter in selected human breast cancer cell lines (HECV as the control). (E) Immunoprecipitation of occludin from MDA-MB-231 and MCF-7 cell lines using 3 antibodies representing 3 different epitopes of occludin (mapping to 3 regions).
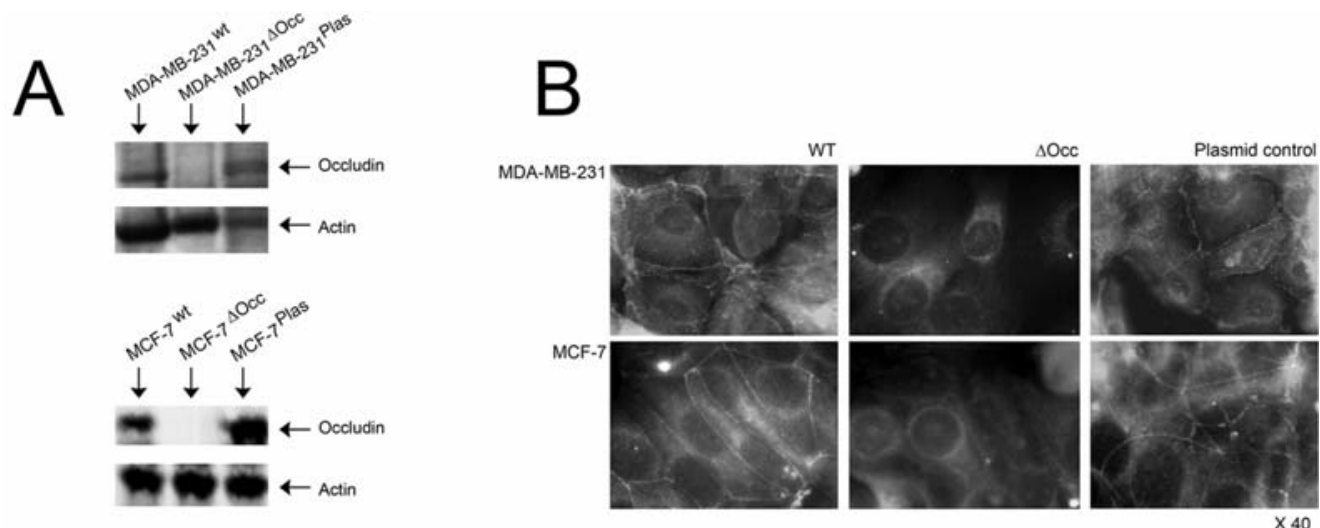

Figure 3. Successful knockdown of occludin in MDA-MB-231 and MCF-7 human breast cancer cell lines. (A) Western blots showing the absence of the occludin protein in MDA-MB-231 (top) and in MCF-7 knockdown cells (bottom). Actin was used as the loading control. (B) Immunofluorescence showing the absence of occludin in the knockdown cells $(\Delta \mathrm{Occ})$.

cells (MDA-MB-231 ${ }^{\Delta \mathrm{Occ}} 0.0109 \pm 0.013$; MDA-MB-231 ${ }^{\mathrm{wT}}$ $0.285 \pm 0.014, \mathrm{p}=0.0009$; MDA-MB-231 $1^{\text {Plas }} 0.286 \pm 0.017$, $\mathrm{p}=0.002)$. Similarly, the occludin knockdown also reduced the adhesion of the MCF-7 cells (MCF-7 $\triangle \mathrm{Occc} 0.039 \pm 0.008$ vs. MCF-7 ${ }^{\text {WT }} 0.052 \pm 0.006, p=0.18$ and vs. MCF- $7^{\text {Plas }}$ $0.049 \pm 0.002, \mathrm{p}=0.17)$ but this did not reach significance 
A Growth of MDA-MB-231 human breast cancer cells

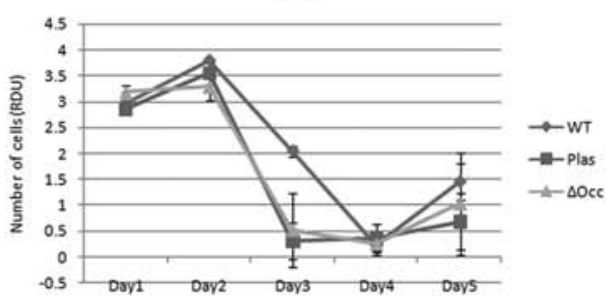

Invasion of MDA-MB-231 human breast cancer cells with/without HGF $(25 \mathrm{ng} / \mathrm{ml})$

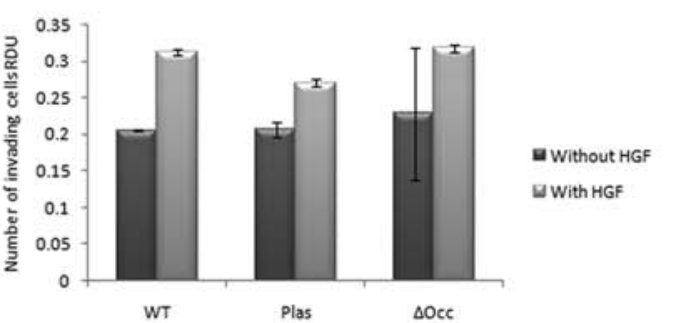

WT

$\triangle \mathrm{Oce}$
$\mathrm{B}$

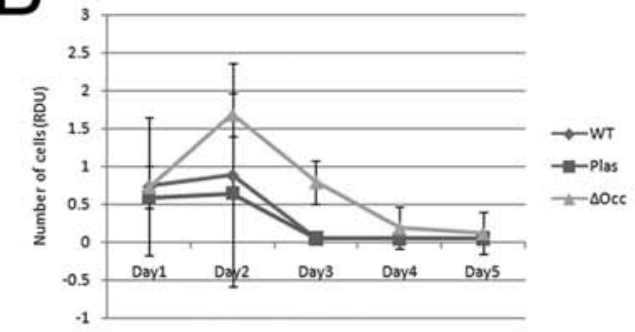

D Invasion of MCF-7 human breast cancer cells with/without HGF $(25 \mathrm{ng} / \mathrm{ml})$

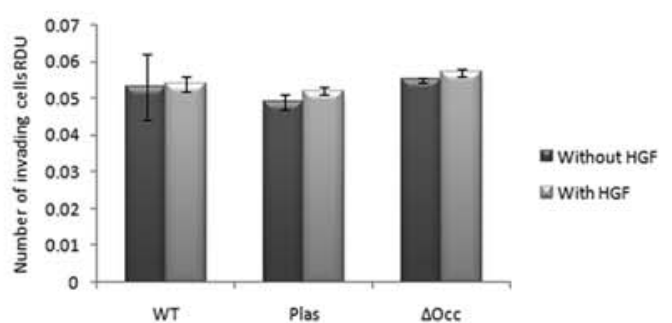

E

Adhesion of MDA-MB-231 human breast cancer cells with/without HGF $(25 \mathrm{ng} / \mathrm{ml})$

$\mathrm{F}$

Adhesion of MCF-7 human breast cancer cells with/without HGF $(25 \mathrm{ng} / \mathrm{ml})$
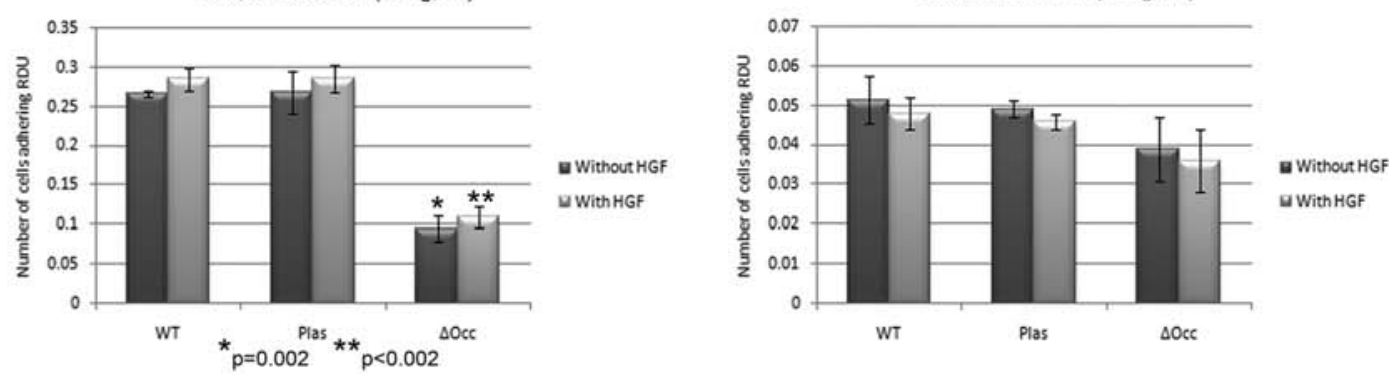

G

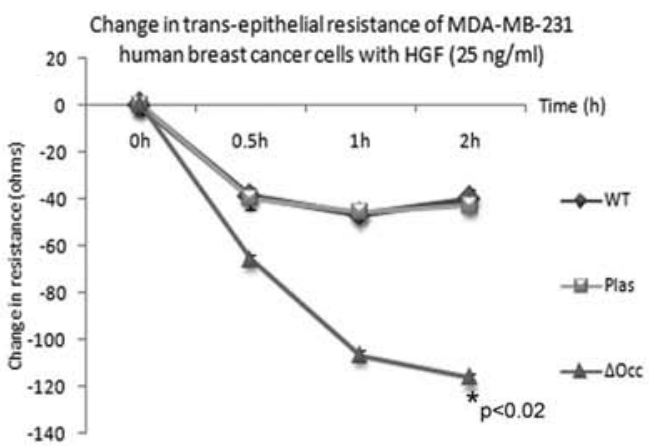

$\mathrm{H}$
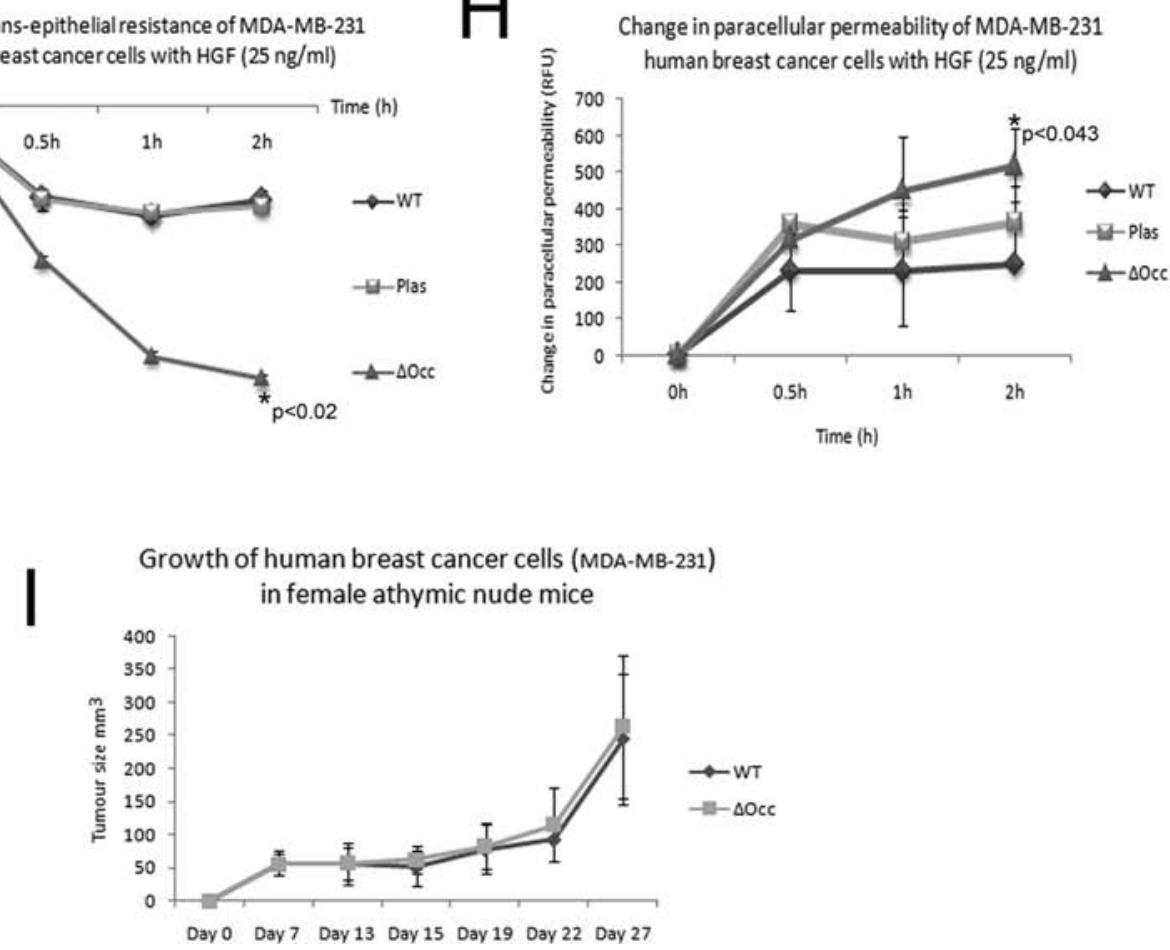

Figure 4. Effect of occludin knockdown on the behaviour of human breast cancer cell lines. In vitro growth assay of (A) MDA-MB-231 and (B) MCF-7 cells comparing $\Delta$ Occ with the wild-type (WT) and plasmid control (Plas). Invasion of (C) MDA-MB-231 and (D) MCF-7 cells, as above, using HGF (25 ng/ml) to promote invasive behaviour. Adhesion to basement membrane of (E) MDA-MB-231 and (F) MCF-7 cells, as above. (G) Change in TER of MDA-MB-231 knockdown cells and (H) change in PCP of the same cells. (I) In vivo growth of knockdown MDA-MB-231 cells. 
A

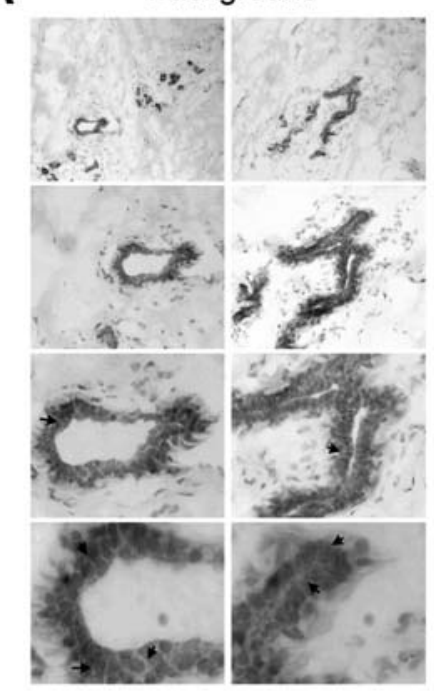

Tumour

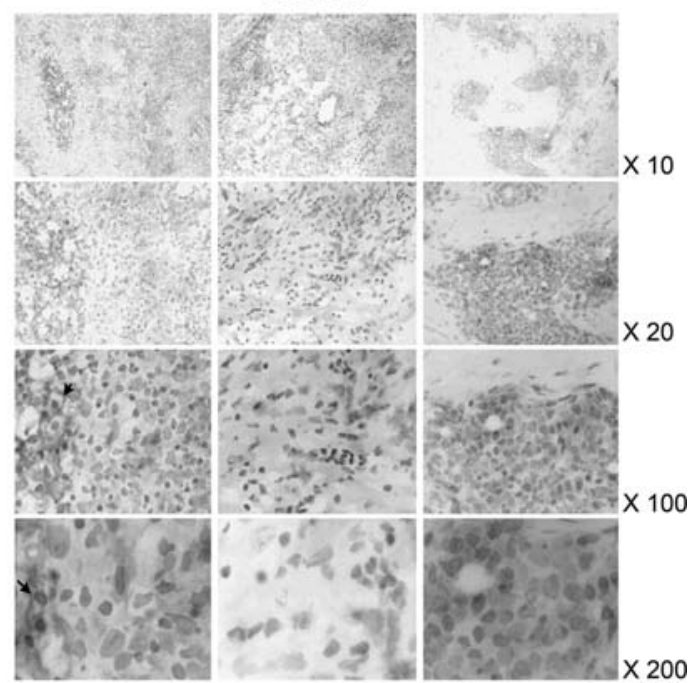

B

Staining intensity for occludin in human breast tissues

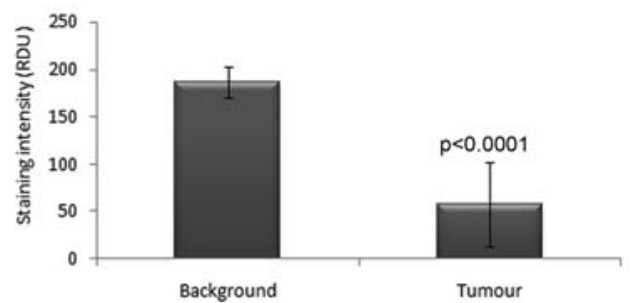

Figure 5. (A) Representative tissue sections stained to show the presence of occludin (background) and the absence of occludin (tumour) in human breast cancer, x100 magnification. The negative and positive controls for the staining are also shown (bottom). (B) Densitometry of the sections to show the significant reduction of occludin staining in the tumour sections $(\mathrm{n}=15)$.

(Fig. 4F). This remained true even after the application of HGF $(25 \mathrm{ng} / \mathrm{ml})$, which in these cells reduced adhesiveness (MCF-7 ${ }^{\triangle \mathrm{Occ}} 0.036 \pm 0.007$ vs. MCF-7wT $0.048 \pm 0.004, \mathrm{p}=0.14$ and vs. MCF- $\left.7^{\text {Plas }} 0.0469 \pm 0.001, \mathrm{p}=0.13\right)$.

Changes in TJ function of occludin knockdown cells. MDAMB-231 cells were then further assessed for the effect of occludin knockdown on TJ functionality, in the same manner as using changes in TER and in paracellular permeability (PCP). The knockdown of occludin resulted in a marked reduction in TER over 2 -h treatment with HGF $(25 \mathrm{ng} / \mathrm{ml})$ compared to the control cells [changes in TER (ohms) within $2 \mathrm{~h}$ : MDA-MB-231 ${ }^{\triangle \mathrm{Occ}}-116.33 \pm 1.74$; MDA-MB$231^{\text {WT }}-40.3 \pm 4.44, \mathrm{p}=0.02$; MDA-MB-231 ${ }^{\text {Plas }}-43 \pm 27$, $\mathrm{p}=0.004]$ (Fig. 4G). This was reflected by a concurrent increase in PCP over the same period of time [changes in PCP (RFU) within 2 h: MDA-MB-231 ${ }^{\triangle \mathrm{Occ}} 520 \pm 100$; MDAMB-231 ${ }^{\text {WT }} 250 \pm 10, p=0.04$; MDA-MB-231 $1^{\text {Plas }} 360 \pm 100$, $\mathrm{p}=0.043$ ] (Fig. 4H).

In vivo tumour growth of occludin knockdown cells. After 27 days of growth, the occludin knockdown did not significantly affect the growth rate of the MDA-MB-231 human breast cancer cells in the athymic nude mouse model (final tumour volume $\mathrm{mm}^{3}$ : MDA-MB-231 ${ }^{\mathrm{\Delta Occ}} 263.028 \pm 108.657$ vs. MDAMB-231 ${ }^{\text {WT }} 244.45 \pm 98.28, \mathrm{p}=0.92$ ) (Fig. 4I). This reflects the in vitro growth of these cells.
Distribution and expression of occludin in tumour and background cancer tissues. We carried out an immunohistological study to assess the location, distribution and the degree of staining of occludin using 10 pairs of matched samples (tumour and background tissue). In normal mammary tissues, occludin appeared as strong staining in the epithelial and endothelial cell lining vessels (black arrows) and ducts with no staining of cells in the stroma (Fig. 5A, background, increasing magnification). The staining for occludin within the tumour sections was, however, greatly decreased in both the cancer and surrounding cells, as well as in their lining vessels (Fig. 5A, tumour, increasing magnification). This is illustrated by the transition seen between the tumour and the associated normal/background tissue as shown in Fig. 5A. Moreover, the staining distribution within the cells from the background tissues was correctly located at the junctional regions of the cells, plainly at the TJ (black arrows). No such distribution was observed in the cells from the tumour sections, where little staining even in the cytoplasm was observable. Thus, the overall staining intensity was reduced in the tumour cells, compared to the normal/ background sections, as was assessed using image analysis (tumour mean \pm SD 57.6 \pm 43.91 vs. background $186.53 \pm 16.98, \mathrm{p}<0.00001)$ (Fig. 5B).

When the occludin expression was examined at the mRNA level using quantitative PCR, the levels were not significantly different between the tumour and background tissue (tumour 

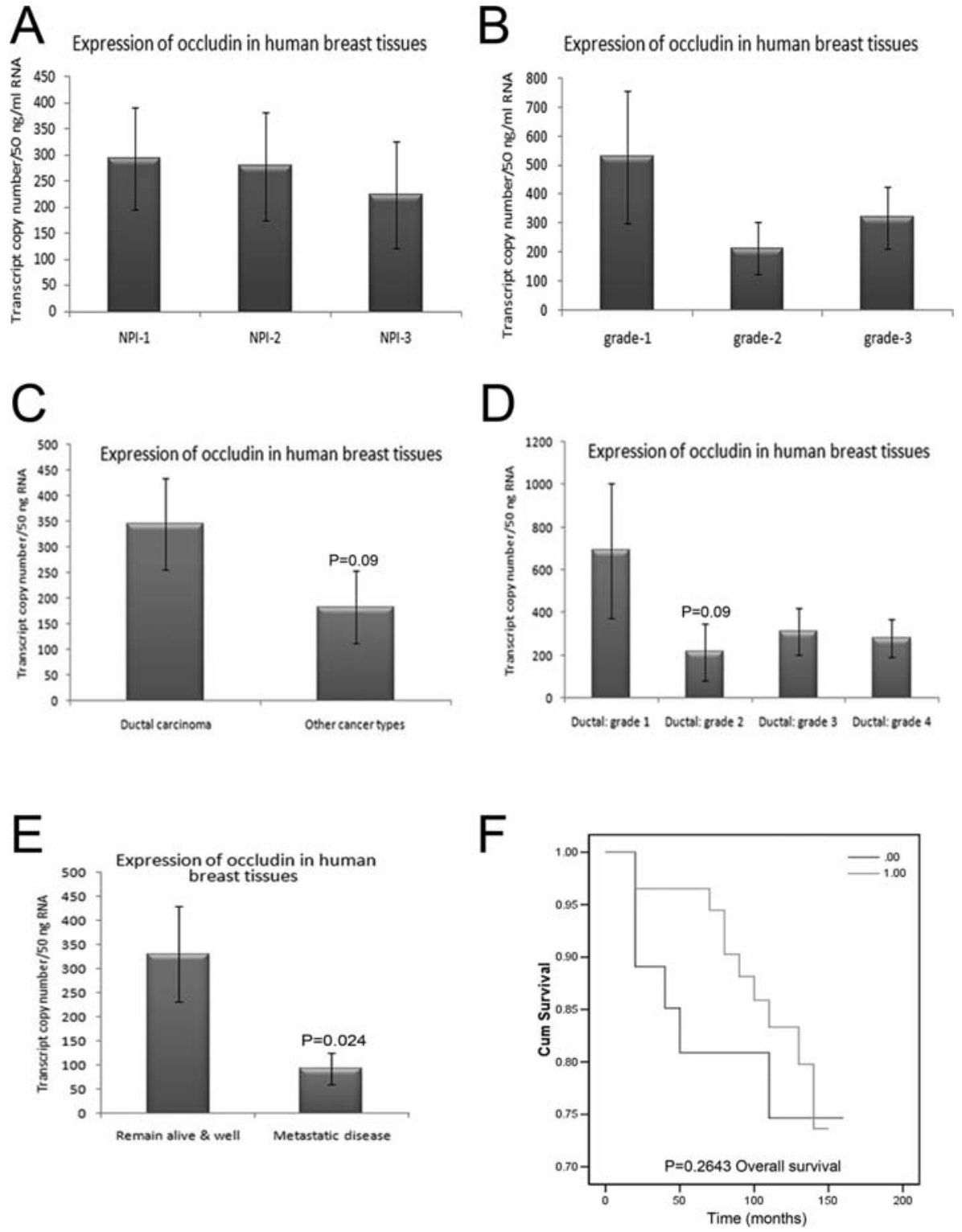

Figure 6. Q-PCR showing the changes in the copy number of occludin in patient tissues (transcript copy number/50 ng/ml RNA). (A) The levels of occludin decreased with increasing NPI status. (B) Occludin is reduced in grade 2-3 tumours. (C) The expression of occludin was higher in ductal carcinoma compared to other types. (D) In the breast tissue cohort used, occludin was reduced with increasing grade in the ductal tumours. (E) Patients who had metastatic disease had significantly reduced levels of occludin $(\mathrm{p}=0.024)$. (F) Survival curve of patients in the current cohort.

mean \pm SE $315.2 \pm 70.9$ vs. background $184.6 \pm 62.1, \mathrm{p}=0.17$ ) There was no significant difference in the expression between the node-positive and the node-negative tumours

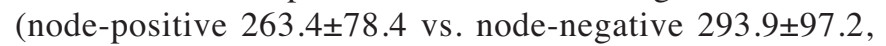
$\mathrm{p}=0.81)$.

Correlation of occludin expression with prognosis and staging. The Nottingham Prognostic Index (NPI) was used as the parameter to assess the prognosis of the patients, in that patients with an NPI value of $<3.4$ (NPI-1) were regarded to have good prognosis, those with a value of 3.4-5.4 (NPI-2) moderate prognosis, and those with a value of NPI $>5.4$ (NPI-3) poor prognosis. The formula for NPI being: NPI = [0.2 x size $\mathrm{cm}]+$ grade $(1-3)+$ nodal status $(1-3)$. There was a stepwise decrease in the occludin expression with poor prognosis (Fig. 6A), i.e. NPI-2-3 tumours (NPI >3.4),

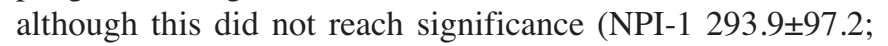

NPI-2 279 \pm 103 ; NPI-3 224 \pm 103 ; p $>0.13$ ). The levels of the molecules were also analyzed against the grade of tumours and also showed a decrease in occludin expression in grade- 2 and -3 tumours, but this did not reach significance (grade-1,

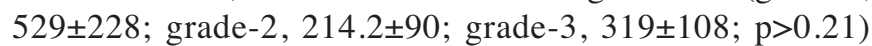
(Fig. 6B). No trend was observed with the TNM tumour status.

Correlation with ER status indicated that occludin was reduced in the ER-positive tumours (ER-negative $384 \pm 115$ vs. ER-positive $217.3 \pm 63.2, \mathrm{p}=0.21$ ) with a reduction also in the expression in the ERß-negative vs. the ERß-positive tumours (337.1 \pm 92.1 vs. $256 \pm 118$, respectively, $\mathrm{p}=0.59)$. Interestingly, the occludin expression was lower in lobular cancers compared to the ductal type (lobular, 236 \pm 125 ; ductal, 345.4 \pm 88.8 ) although significance was not reached $(p=0.37)$. There was an increased expression of occludin in ductal cancers compared to other types (ductal, 345.4 \pm 88.8 ; 
others, 131.2 \pm 96.8$)$ which approached significance $(\mathrm{p}=0.09)$ (Fig. 6C). Moreover, there was a striking reduction in occludin expression in higher grade ductal tumours (Fig. 6D).

Expression of occludin and clinical outcome following 10year follow-up. Fig. 6E shows data comparing patients who remained alive and well to those who had metastatic disease after a median follow-up of 120 months. Those patients with metastatic disease had significantly reduced levels of occludin expression compared to those without disease (metastatic

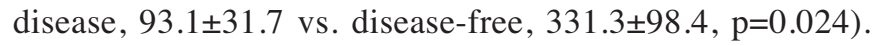
Patients who had local recurrences also showed decreased occludin expression when compared to those who remained disease-free (local recurrence, 290 \pm 203 , p=0.86). Patients who died of breast cancer did not have significantly reduced levels of occludin compared to the patients who remained alive and well $(328.9 \pm 87.6, \mathrm{p}=0.99)$. Overall poor outcomes were reduced compared to those who remained alive and well (269.3 $\pm 64.7, p=0.6)$. These data show that reduced occludin expression is associated with poor prognosis and outcome in patients with metastatic disease.

Survival curves (over 120 months) showed that reduced occludin transcript levels were associated with poor overall survival in patients with breast cancer as was analysed using the Cox-Proportion-Hazardous test $(\mathrm{p}=0.2643)$, Fig. 6F.

\section{Discussion}

This study shows that occludin is aberrantly expressed in both human breast cancer cell lines and in human breast tumour tissues, due to pre- and possibly post-translational events. The knockdown of occludin in human breast cancer cell lines leads to the reduced TJ function in MDA-MB-231 and MCF-7 cells and the reduced ability to adhere to the basement membrane. In vitro and in vivo growth was, however, not affected. Moreover, the expression of occludin was significantly reduced in human breast tumour tissues when compared to background ones, as revealed by immunohistochemistry, with Q-PCR analysis revealing that the loss of occludin was significantly correlated with patients who had died of metastatic disease.

Although occludin was one of the first TJ proteins discovered, its function in the TJ is poorly defined (30). The suppression of occludin is associated with a decrease in the claudin- 1 and -7 and an increase in the claudin-3 and -4 expression. It has been indicated that occludin transduces external (apoptotic cells) and intra-membrane (rapid cholesterol depletion) signals via a Rho signalling pathway that, in turn, elicits the re-organization of the actin cytoskeleton. Impaired signalling in the absence of occludin can also alter the dynamic behaviour of TJ strands, as reflected by the increase in permeability to large organic cations, although however, the permeability of ion pores formed by claudins, is less affected.

This study has shown that there were a few variants of occludin observable in the human breast tissues and human cell lines investigated. The human breast tissues showed aberrant/truncated forms of occludin, with a significant number (4/6) not expressing the C-terminal. Overall, only 3 cell lines expressed the full-length version of occludin. No methylation of the occludin promoter was observed, and therefore we can conclude that occludin undergoes a number of translational modifications. We also decided to investigate the human breast cancer cell lines MDA-MB-231 and MCF-7, as we had previously observed aberrant expression of occludin by these cells (23). Immuno-precipitation using 3 occludin antibodies and 3 different epitopes revealed that the $\mathrm{N}$-terminus was able to pull out only the $82 \mathrm{kDa}$ form of occludin, but that both the H-279 and C-terminus epitopes pulled out 2 forms of occludin protein in both cell lines, the $82 \mathrm{kDa}$ form and another truncated form of $\sim 70 \mathrm{kDa}$ which corresponds to the form we had previously observed (24). This form does not correspond to known phosphorylated forms of the protein and therefore demonstrates that the occludin protein in these cell lines is truncated, possibly due to the loss of the N-terminus.

This is not the first time that alternate forms of occludin have been observed. An alternatively spliced form of occludin, occludin 1B was identified in MDCK cells and cultured T84 human colon cancer cells (31). There are 2 gene products, the larger, predominant product corresponding to the canonical occludin (TM4+), whilst the smaller product exhibits a $162 \mathrm{bp}$ deletion encoding the entire TM4 and immediate C-terminal flanking region (TM4-) (32). The deleted section corresponds to exon 4, suggesting that TM4- is an alternatively spliced isoform. TM4- was also found in monkey epithelial cells, but not in murine or canine ones. The staining of occludin in Caco-2 cells with a C-terminal occludin antibody revealed weak, discontinuous staining restricted to the periphery of subconfluent islands. A weak band at $58 \mathrm{kDa}$ (smaller than the predominant band at $65 \mathrm{kDa}$ ) corresponded to the predicted mass after blotting. The authors suggest that the TM4- isoform is up-regulated in the subconfluent cells, and that it is translated at low levels in specific conditions and could contribute to the regulation of occludin function, i.e. if occludin has no C-terminus, it cannot bind to ZO-1. Such alternatively spliced forms could therefore explain the variants found in our study, particularly the loss of the N-teminus region (for correct assembly within the $\mathrm{TJ}$ ) and the loss or truncation of the C-terminal region. This is essential for the correct intracellular trafficking of occludin to the membrane and binding to the GUK sites of ZO-1 (33). Moreover, the loss of the first transmembrane region indicates a reason as to why, even though occludin is present, it does not contribute to the function of the TJ structure. Zeng et al (34) observed that in human cervical cells, 17ß-estradiol modulated the expression of the $65 \mathrm{kDa}$ occludin form at low concentrations (1-10 nM), but that at higher concentrations $(100 \mathrm{nM})$ it induced an expression of a $50 \mathrm{kDa}$ form of occludin that was the result of the post-translational up-regulation of the occludin turnover, including synthesis and degradation. This kind of modification is clearly not a contributory factor in our study.

It has also been shown that in contrast to earlier studies, the complete or partial truncation of the C-terminal of occludin alone, does not prevent the correct targeting of occludin to the TJ in epithelial cells, and that TM4 deletions were most important for correct targeting, leading to occludin that was retained intracellularly (35). It is becoming increasingly clear that occludin is a complex and multi-functional protein. The 
loss or truncation of occludin also has repercussions on other proteins in epithelial cells. It has also been shown that occludin has a potent inhibitory effect on Raf1-mediated tumourigenesis in epithelial derived cancers, with the second extracellular loop being critical for this behaviour (36).

We also considered the effect of occludin knockdown in the human breast cancer cell lines MDA-MB-231 and MCF-7. The successful knockdown of occludin resulted in cells with a dramatically altered phenotype with regards to changes in adherence to the basement membrane and in the loss of TER and increased PCP in both cell lines. This indicates that the loss of occludin leads to a more aggressive phenotype in these cells, particularly the phenotype of MCF-7 cells, which is usually the less aggressive cell line. Interestingly, there was little change in the in vitro and in vivo growth rates of the MDA-MB-231 occludin knockdown. However, the MCF-7 knockdown showed an increased in vitro growth rate, commensurate with an increased aggressive phenotype. Previous studies have highlighted the results of occludin overexpression $(37,38)$. The forced expression of occludin in MCF-7, murine breast and melanoma cancer cell lines resulted in cells with an enhanced sensitivity to apoptogenic factors, therefore leading to the inhibition of tumourigenicity of transfected cells and demonstrating that the epigenetic silencing of occludin results in the acquisition of apoptotic resistance, identifying occludin as a likely candidate for a tumour-suppressor gene in certain tumour types (37). Osanai et al (38) demonstrated that the overexpression of occludin induced anoikis and promoted oxidative stress-induced premature senescence in breast carcinoma cells, accompanied by the up-regulation of negative cell cycle regulators, and thereby suggesting that the loss of occludin expression could be involved in the senescence-escape program during breast cancer progression.

Certain studies have suggested that some of the cell adhesion and cytoskeletal proteins could subserve an additional and important function, namely the suppression of the malignant phenotype of cells in tumourigenesis (39). Whilst the barrier and fence functions of TJs have been well appreciated in the past, it was not till later that the concept of the TJ as a complex, multiprotein structure with roles in other cellular processes such as cell polarity, proliferation and differentiation, was recognised (40). Moreover, it is becoming increasingly clear that the development of human cancer is frequently associated with the failure of epithelial cells to form TJs and establish correct apicobasal polarity (41).

Our study examined the expression of occludin in human breast tissues. The occludin expression was significantly reduced as was observed from the immunohistochemical staining of the paired tumour/background tissues. Moreover, Q-PCR analysis revealed that the loss of occludin was associated with the increasing aggressiveness of tumours (as ascertained using NPI scores and tumour grade) and with tumour type. The loss of occludin was significantly associated with death from metastatic disease in patients with breast cancer. Although the loss of occludin has been described in other cancer types (42-47), there has been no comprehensive study on human breast cancer. Thus, this is the first study demonstrating that the reduced occludin expression can be linked to the disease process in human breast cancer. The association of occludin with metastatic disease in human breast cancer patients is an area that deserves further scrutiny.

In conclusion, we demonstrate here for the first time that occludin is differentially expressed in breast tumour tissues and in human breast cancer cell lines. The changes in occludin message indicate that variants are expressed in tumour tissue. The loss of/truncation of the $\mathrm{N}$-terminus indicates the reduced assembly of the TJ structure and the reduced maintenance of the barrier function. The loss of C-terminal expression suggests the reduced intracellular trafficking of occludin to the basolateral membrane and binding to ZO-1, resulting in reduced TJ anchoring, assembly and cell-cell adhesion. This has clear repercussions as to the importance of occludin in maintaining TJ integrity in breast tissues. Such inappropriate expression could play a part in breast cancer development. The knockdown of endogenous occludin in human breast cancer cells leads to the profoundly reduced junctional integrity, loss of tightness and increased invasive potential of these cells. Moreover, the loss of occludin expression is associated with metastatic disease in patients with breast cancer. It is becoming increasingly clear that occludin is essential for the correct functioning of the TJ in human breast epithelial cells.

\section{Acknowledgements}

We wish to thank Dr Gregory M. Harrison, Mrs. Jane Lane and Mr. Gareth Watkins for their experimental support. Funding for this study came from Cancer Research Wales, (grant no. WGJ2006).

\section{References}

1. Furuse M, Hirase T, Itoh M, Nagafuchi A, Yonemura S, Tsukita S and Tsukita S: Occludin: a novel integral membrane protein localizing at tight junctions. J Cell Biol 123: 1777-1788, 1993.

2. Itoh M, Morita $\mathrm{K}$ and Tsukita S: Characterization of ZO-2 as a MAGUK family member associated with tight as well as adherens junctions with a binding affinity to occludin and alpha catenin. J Biol Chem 274: 5981-5986, 1999.

3. Tsukita $\mathrm{S}$ and Furuse M: Occludin and claudins in tight-junction strands: leading or supporting players? Trends Cell Biol 9: 268-273, 1999.

4. Furuse M, Fujita K, Hiiragi T, Fujimoto K and Tsukita S: Claudin-1 and -2: novel integral membrane proteins localizing at tight junctions with no sequence similarity to occludin. J Cell Biol 141: 1539-1550, 1998.

5. Denker BM and Nigam SK: Molecular structure and assembly of the tight junction: Am J Physiol 274: F1-F9, 1998.

6. Matter K and Balda MS: Biogenesis of tight junctions: the Cterminal domain of occludin mediates basolateral targeting. J Cell Sci 111: 511-519, 1998 .

7. Jiang WG, Bryce RP, Horrobin DF and Mansel RE: Regulation of tight junction permeability and occludin expression by polyunsaturated fatty acids. Biochem Biophys Res Commun 244: 414-420, 1998

8. Van Itallie CM and Anderson JM: Occludin confers adhesiveness when expressed in fibroblasts. J Cell Sci 110: 1113-1121, 1997.

9. Sakakibara A, Furuse M, Saitou M, Ando-Akatsuka Y and Tsukita S: Possible involvement of phosphorylation of occludin in tight junction formation. J Cell Biol 37: 1393-1401, 1997.

10. Wong V: Phosphorylation of occludin correlates with occludin localization and function at the tight junction. Am J Physiol 273: C1859-C1867, 1997.

11. Farshori P and Kachar B: Redistribution and phosphorylation of occludin during opening and resealing of tight junctions in cultured epithelial cells. J Membr Biol 170: 147-156, 1999. 
12. Wachtel M, Frei K, Ehler E, Fontana A, Winterhalter K and Gloor SM: Occludin proteolysis and increased permeability in endothelial cells through tyrosine phosphatase inhibition. J Cell Sci 112: 4347-4356, 1999.

13. Tobioka H, Sawada N, Zhong Y and Mori M: Enhanced paracellular barrier function of rat mesothelial cells partially protects against cancer cell penetration. Br J Cancer 74: 439-445, 1996.

14. Kominsky SL, Argani P, Korz D, Evron E, Raman V, Garrett E, Rein A, Sauter G, Kallioniemi OP and Sukumar S: Loss of the tight junction protein claudin-7 correlates with histological grade in both ductal carcinoma in situ and invasive ductal carcinoma of the breast. Oncogene 22: 2021-2033, 2003.

15. Martin TA, Mansel RE and Jiang WG: Antagonistic effect of $\mathrm{NK} 4$ on $\mathrm{HGF} / \mathrm{SF}$ induced changes in the transendothelial resistance (TER) and paracellular permeability of human vascular endothelial cells. J Cell Physiol 92: 268-275, 2002.

16. Ren J, Hamada J, Takeichi N, Fujikawa S and Kobayashi H: Ultrastructural differences in junctional intercellular communication between highly and weakly metastatic clones derived from rat mammary carcinoma. Cancer Res 50: 358-362, 1990.

17. Satoh H, Zhong Y, Isomura H, Saitoh M, Enomoto K, Sawada N and Mori M: Localization of 7H6 tight junction-associated antigen along the cell border of vascular endothelial cells correlates with paracellular barrier function against ions, large molecules, and cancer cells. Exp Cell Res 222: 269-274, 1996.

18. Hoevel T, Macek R, Mundigl O, Swisshelm K and Kubbies M Expression and targeting of the tight junction protein CLDN1 in CLDN1-negative human breast tumor cells. J Cell Physiol 191: 60-68, 2002

19. Kramer F, White K, Kubbies M, Swisshelm K and Weber BH: Genomic organization of claudin-1 and its assessment in hereditary and sporadic breast cancer. Hum Genet 107: 249-256, 2000 .

20. Hoover KB, Liao SY and Bryant PJ: Loss of the tight junction MAGUK ZO-1 in breast cancer: relationship to glandular differentiation and loss of heterozygosity. Am J Pathol 153: 1767-1773, 1998.

21. Chlenski A, Ketels KV, Korovaitseva GI, Talamonti MS, Oyasu R and Scarpelli DG: Organization and expression of the human zo-2 gene (tjp-2) in normal and neoplastic tissues. Biochim Biophys Acta 493: 319-324, 2000.

22. Bell J, Walsh S, Nusrat A and Cohen C: Zonula occludens-1 and Her-2/neu expression in invasive breast carcinoma. Appl Immunohistochem Mol Morphol 11: 125-129, 2003.

23. Martin TA, Watkins G, Mansel RE and Jiang WG: Hepatocyte growth factor disrupts tight junctions in human breast cancer cells. Cell Biol Int 28: 361-371, 2004.

24. Martin TA, Watkins G, Mansel RE and Jiang WG: Loss of tight junction plaque molecules in breast cancer tissues is associated with a poor prognosis in patients with breast cancer. Eur J Cancer 40: 2717-2725, 2004

25. Martin TA, Das T, Mansel RM and Jiang WG: Enhanced tight junction function in human breast cancer cells by antioxidant, selenium and polyunsaturated lipid. J Cell Biochem 101: 155-166, 2007.

26. Herman JG, Graff JR, Myöhänen S, Nelkin BD and Baylin SB: Methylation-specific PCR: a novel PCR assay for methylation status of CpG islands. Proc Natl Acad Sci USA 93: 9821-9826, 1996.

27. Hiscox S and Jiang WG: Association of the HGF/SF receptor, cmet, with the cell- surface adhesion molecule, E-cadherin, and catenins in human tumour cells. Biochem Biophys Res Commun 261: 406-411, 1999

28. Jiang WG, Davies G, Martin TA, Parr C, Watkins G, Mansel RE and Mason MD: The potential lymphangiogenic effects of hepatocyte growth factor/scatter factor in vitro and in vivo. Int $\mathbf{J}$ Mol Med 16: 723-728, 2005.

29. Martin TA, Parr C, Davies G, Watkins G, Lane J, Matsumoto K, Nakamura T, Mansel RE and Jiang WG: Growth and angiogenesis of human breast cancer in a nude mouse tumour model is reduced by NK4, a HGF/SF antagonist. Carcinogenesis 24: 1317-1323, 2003.
30. Yu AS, McCarthy KM, Francis SA, McCormack JM, Lai J, Rogers RA, Lynch RD and Schneeberger EE: Knockdown of occludin expression leads to diverse phenotypic alterations in epithelial cells. Am J Physiol Cell Physiol 288: C1231-C1241, 2005.

31. Muresan Z, Paul DL and Goodenough DA: Occludin 1B, a variant of the tight junction protein occludin. Mol Biol Cell 11: 627-634, 2000

32. Ghassemifar MR, Sheth B, Papenbrock T, Leese HJ, Houghton FD and Fleming TP: Occludin TM4(-): an isoform of the tight junction protein present in primates lacking the fourth trans-membrane domain. J Cell Sci 115: 3171-3180, 2002.

33. Imamura Y, Itoh M, Maeno Y, Tsukita S and Nagafuchi A: The tight junction protein occludin and the adherens junction protein $\alpha$-catenin share a common interaction mechanism with ZO- 1 . J Biol Chem 280: 3747-3756, 2005.

34. Zeng R, Li $\mathrm{X}$ and Gorodeski GI: Estrogen abrogates transcervical tight junctional resistance by acceleration of occludin modulation. J Clin Endocrinol Metab 89: 5145-5155, 2004.

35. Subramanian VS, Marchant JS, Ye D, Ma TY and Said HM: Tight junction targeting and intracellular trafficking of occludin in polarised epithelial cells. Am J Physiol Cell Physiol 293: C1717-C1726, 2007.

36. Wang Z, Mandell KJ, Parkos CA, Mrsny RJ and Nusrat A: The second loop of occludin is required for suppression of Raf1induces tumour growth. Oncogene 24: 4412-4420, 2005.

37. Osanai M, Murata M, Nishikiori N, Chiba H, Kojima T and Sawada N: Epigenetic silencing of occludin promotes tumourigenic and metastatic properties of cancer cells via modulations of unique sets of apoptosis-associated genes. Cancer Res 66: 9125-9133, 2006.

38. Osanai M, Murata M, Nishikiori N, Chiba H, Kojima T and Sawada N: Occludin-mediated premature senescence is a failsafe mechanism against tumourigenesis in breast carcinoma cells. Cancer Sci 98: 1027-1034, 2007.

39. Chlenski A, Ketels KV, Tsao MS, Talamonti MS, Anderson MR, Oyasu R and Scarpelli DG: Tight junction protein ZO-2 is differentially expressed in normal pancreatic ducts compared to human pancreatic adenocarcinoma. Int J Cancer 82: 137-144, 1999.

40. Shin K, Fogg VC and Margolis B: Tight junctions and cell polarity. Annu Rev Cell Dev Biol 22: 207-235, 2006.

41. Latorre IJ, Roh MH, Frese KK, Weiss RS, Margolis B and Javier RT: Viral oncoprotein-induced mislocalization of select PDZ proteins disrupts tight junctions and causes polarity defects in epithelial cells. J Cell Sci 118: 4283-4293, 2005.

42. Tobioka H, Isomura H, Kokai Y,Tokunaga Y, Yamaguchi J and Sawada N: Occludin expression decreases with the progression of human endometrial carcinoma. Hum Pathol 35: 159-164, 2004.

43. Billings SD, Walsh SV, Fisher C, Nusrat A, Weiss SW and Folpe AL: Aberrant expression of tight junction-related proteins ZO-1, claudin-1 and occludin in synovial sarcoma: an immunohistochemical study with ultrastructural correlation. Mod Pathol 17: 141-149, 2004.

44. Davies DC: Blood-brain barrier breakdown in septic encephalopathy and brain tumours. J Anat 200: 639-646, 2002.

45. Busch C, Hanssen TA, Wagener C and OBrink B: Downregulation of CEACAM1 in human prostate cancer: correlation with loss of cell polarity, increased proliferation rate, and Gleason grade 3 to 4 transition. Hum Pathol 33: 290-298, 2002.

46. Papadopoulos MC, Saadoun S, Woodrow CJ, Davies DC, Costa-Martins P, Moss RF, Krishna S and Bell BA: Occludin expression in microvessels of neoplastic and non-neoplastic human brain. Neuropathol Appl Neurobiol 27: 384-395, 2001.

47. Marzioni D, Banita M, Felici A, Paradinas FJ, Newlands E, De Nictolis M, Mühlhauser J and Castellucci M: Expression of ZO-1 and occludin in normal human placenta and in hydatidiform moles. Mol Hum Reprod 7: 279-285, 2001. 